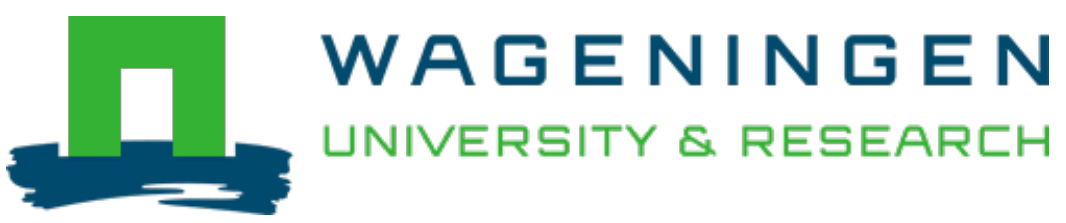

\title{
Evaluating the SandFlow, an acoustic sediment transport sensor
}

\author{
Aeolian Research \\ Rezaei, Mahrooz; Goossens, Dirk; Riksen, Michel J.P.M. \\ https://doi.org/10.1016/j.aeolia.2019.100558
}

This article is made publicly available in the institutional repository of Wageningen University and Research, under the terms of article $25 \mathrm{fa}$ of the Dutch Copyright Act, also known as the Amendment Taverne. This has been done with explicit consent by the author.

Article 25 fa states that the author of a short scientific work funded either wholly or partially by Dutch public funds is entitled to make that work publicly available for no consideration following a reasonable period of time after the work was first published, provided that clear reference is made to the source of the first publication of the work.

This publication is distributed under The Association of Universities in the Netherlands (VSNU) 'Article $25 \mathrm{fa}$

implementation' project. In this project research outputs of researchers employed by Dutch Universities that comply with the legal requirements of Article $25 \mathrm{fa}$ of the Dutch Copyright Act are distributed online and free of cost or other barriers in institutional repositories. Research outputs are distributed six months after their first online publication in the original published version and with proper attribution to the source of the original publication.

You are permitted to download and use the publication for personal purposes. All rights remain with the author(s) and / or copyright owner(s) of this work. Any use of the publication or parts of it other than authorised under article $25 \mathrm{fa}$ of the Dutch Copyright act is prohibited. Wageningen University \& Research and the author(s) of this publication shall not be held responsible or liable for any damages resulting from your (re)use of this publication.

For questions regarding the public availability of this article please contact openscience.library@wur.nl 


\title{
Evaluating the SandFlow, an acoustic sediment transport sensor
}

\author{
Mahrooz Rezaei ${ }^{\mathrm{a}, \mathrm{c}, *}$, Dirk Goossens ${ }^{\mathrm{b}}$, Michel J.P.M. Riksen ${ }^{\mathrm{c}}$ \\ ${ }^{a}$ Department of Soil Science, School of Agriculture, Shiraz University, Shiraz, Iran \\ ${ }^{\mathrm{b}}$ Department of Earth and Environmental Sciences, Katholieke Universiteit Leuven, Geo-Institute, Celestijnenlaan 200 E, 3001 Leuven, Belgium \\ ${ }^{\mathrm{c}}$ Soil Physics and Land Management Group, Wageningen University \& Research, PO. Box 47, 6700 AA Wageningen, The Netherlands
}

\section{A R T I C L E I N F O}

\section{Keywords:}

SandFlow

Sand transport

Wind

Acoustic sensor

\begin{abstract}
A B S T R A C T
The SandFlow is an acoustic device for detecting and measuring aeolian sand transport. It is based on the FlowCapt sensor, an instrument developed to measure aeolian snow transport. This study investigates the performance of the SandFlow in relation to the Saltiphone and the Modified Wilson and Cooke sampler, two devices frequently used in aeolian sand transport. The performance of the SandFlow was tested during three wind erosion events on the Dutch barrier island Terschelling and also in laboratory tests. Results show that the SandFlow adequately registers the periods of aeolian sand transport provided sand transport is sufficiently intense. For low sand transport the SandFlow is less accurate, although the periods with sand transport may still be detected. The sand transport fluxes measured by the SandFlow were lower than those measured by the MWAC although they remained within the same order of magnitude. Laboratory measurements showed that the efficiency of the SandFlow to register sand transport is close to $100 \%$ for sand coarser than $300 \mu \mathrm{m}$. For finer sand, efficiency decreases rapidly although the instrument remains usable for particles coarser than $150 \mu \mathrm{m}$ provided appropriate corrections for efficiency are made. This study shows that the SandFlow can be used for aeolian sand transport provided the erosion event is strong enough and the particles are not too fine.
\end{abstract}

\section{Introduction}

Measuring aeolian sediment transport in real-time remains a challenge in aeolian research, especially if the measurement period takes more than a day or even years. A large variety of real-time sensors is currently available: continuously-weighing sand traps (Lee, 1987; Janssen and Tetzlaff, 1991; Jackson, 1996; Bauer and Namikas, 1998); electronic sensors with a high time resolution like the Sensit and Safire that use a piezoelectric crystal to register sand impacts (Gillette and Stockton, 1989; Stockton and Gillette, 1990; Baas, 2004; Gillies et al., 2006; Lancaster et al., 2010); the Saltiphone (Spaan and van den Abeele, 1991) and Miniphone (Ellis et al., 2009), which are impact sensors that contain a microphone to register grain impacts; and several optical electronic devices like the sand particle counter (SPC) (Mikami et al., 2005), the Wenglor (Hugenholtz and Barchyn, 2011; Barchyn et al., 2014; Duarto-Campos et al., 2017; Bauer et al., 2018; Schmutz et al., 2019), and the SANTRI (Etyemezian et al., 2017). The main problem of most of these sensors is that they are not suitable to measure for long periods under harsh conditions in remote areas. They either need frequent cleaning to maintain their ability to measure transport, or they need power supply. Also, fixed-orientation sensors are not recommended due to shifts in wind direction.
The SandFlow (SF4) (Fig. 1A) is a new acoustic device to detect and measure aeolian sediment transport. It was developed by IAV Technologies SARL - ISAW Products Division. The SandFlow is based on the FlowCapt sensor (Chritin et al., 1999; Cierco et al., 2007), which was designed to measure aeolian snow transport. The SandFlow works similarly to the FlowCapt anemo-driftometer and measures both wind velocity and sediment flux. The sensor consists of a hard thermopowder lacquer tube fitted with electroacoustic transducers (Fig. 1A). The detection principle is well described by Chritin et al. (1999) and is based on mechanical-acoustical coupling. The sensor is composed of a closed pipe containing electro-acoustic transducers and a powering, filtering and amplifying unit. The sensing part of the SandFlow is a cylindrical, anti-abrasion, anti-adhesion and anti-rime coated tube supported by two stainless steel arms. When the sensor is placed into a particle stream, the particles hit the sensor pipe, inducing acoustical pressure. The pressure is picked up by the transducers. The electrical output is filtered and time-averaged in pre-defined frequency ranges to provide a signal proportional to the particles' flux $\mathrm{Q}\left(\mathrm{kg} \mathrm{m}^{-2} \mathrm{~s}^{-1}\right)$. The formal relationship between the measured acoustic pressure and the particle flux $Q$ requires the determination of the mechanical-acoustical coupling equations for the sensor, according to suitable hypotheses about particle impact. The wind velocity is determined on a similar

\footnotetext{
* Corresponding author.

E-mail address: mahrooz.rezaei@shirazu.ac.ir (M. Rezaei).
} 


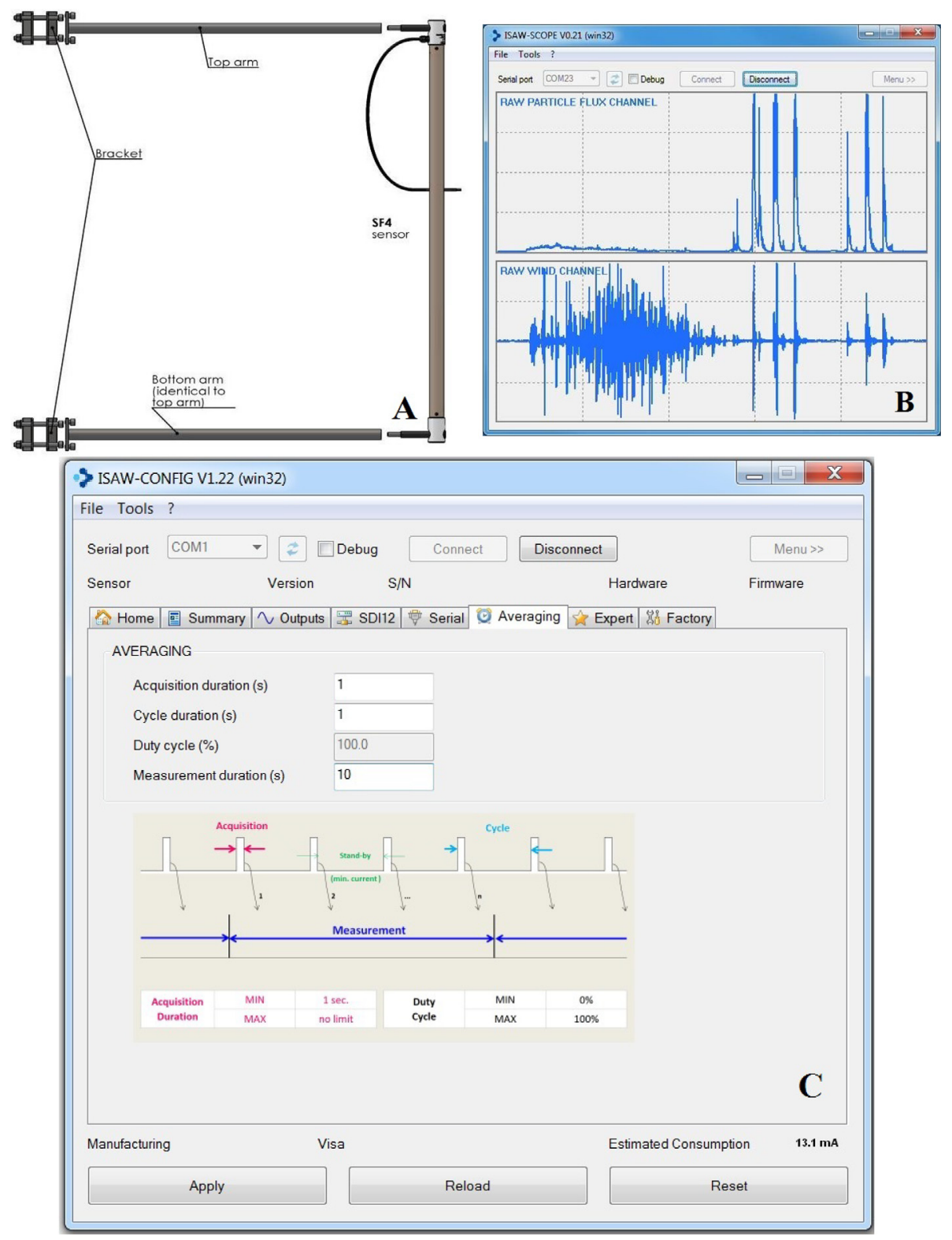

Fig. 1. A: The SF4 Sensor; B: SF4 operation; and C: the averaging panel for setting the measurements.

Table 1

Voltage ranges and measuring scales of SF4.

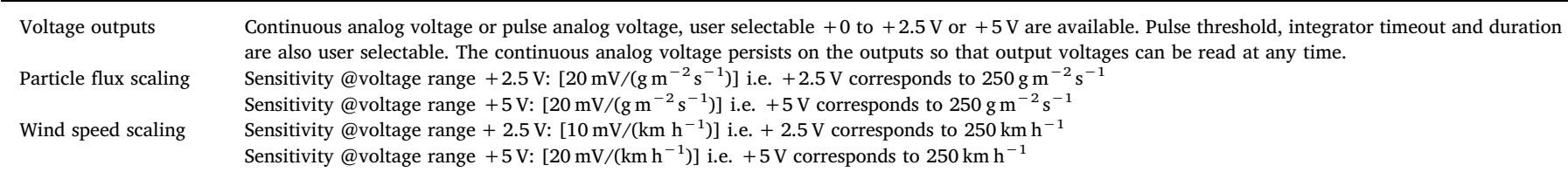

principle: the wind interacts with the body of the sensor and induces acoustic pressure into air enclosures. Sand impacts and wind friction induce changes in the internal acoustic pressure. The two excitations are discriminated as independent signals as a result of a specific acoustic, mechanical and electronic design. Suitable sensitivity can be obtained by optimizing the body shape and structure to the expected wind velocities (Chritin, 1998). The frequency with which the data can be stored and downloaded can be adjusted by the operator. There is an averaging panel in the SandFlow toolbox which allows the user to select all the measurement settings (Fig. 1C). Voltage ranges and measuring scales are described in Table 1.
The SandFlow is a robust omnidirectional sensor, which could make the instrument very suitable for long-time monitoring. However, no test data are yet available in which the sensor is compared to other equipment for aeolian sediment transport measurements. The main objective of this study is to test the capability of the SandFlow to measure aeolian sand transport by comparing the sensor to other aeolian devices in a field experiment. Additional to this, we also tested the effect of particle size and kinetic energy on the efficiency of the sensor by performing drop tests in the laboratory.

In this study three different configurations of the SandFlow sensor were tested: (1) the standard configuration (SF4), which consists of a 1- 
$m$ long sensor pipe with the transducers' unit positioned at the top end; and two experimental variants: (2) the bicephal configuration (Bicephal SF4-B), which is similar to the SF4 sensor but has a second transducers' unit at the bottom of the sensor; and (3) a short SF4 sensor of which the sensor pipe was reduced to $0.33 \mathrm{~m}$ (SF4-short).

\section{Methodology}

\subsection{Field measurements}

To test the capability of the SandFlow to measure aeolian sand transport, we compared the sampler to two other instruments that are regularly used in sand transport studies: the Modified Wilson and Cooke sampler (MWAC) and the Saltiphone. The MWAC is a passive device for simultaneously measuring sand transport at different heights above the surface (Sterk and Raats, 1996). The Saltiphone records the impacts of saltating grains on a microphone. In a recent experiment (Goossens et al., 2018), the operation of these two instruments was already compared during field measurements on the Dutch coast near The Hague.

The test was performed from 7 till 24 August 2017 on a wide flat beach at the Dutch barrier island Terschelling (Fig. 2). Instruments were installed on a NW-SE oriented row on the beach, perpendicular to the dominant wind direction at Terschelling. To measure the weather conditions, a 3-m tall wind mast was installed close to the test site (Fig. 2). The mast was equipped with 5 cup anemometers at $66 \mathrm{~cm}$, $106 \mathrm{~cm}, 145 \mathrm{~cm}, 166 \mathrm{~cm}$ and $205 \mathrm{~cm}$ above the beach floor and a wind vane at the top. A tipping bucket was installed on a separate pole of
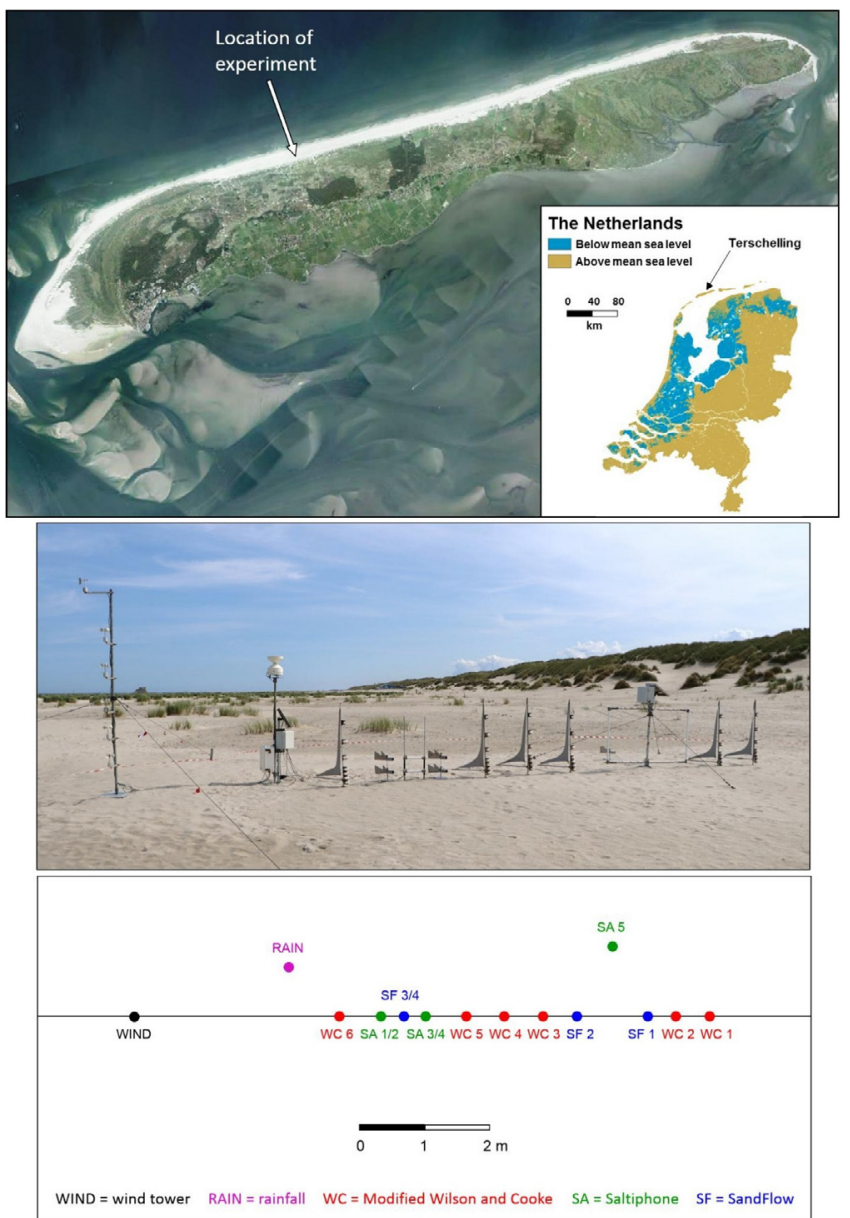

Fig. 2. Location of the experiment on the island of Terschelling and experimental setup.

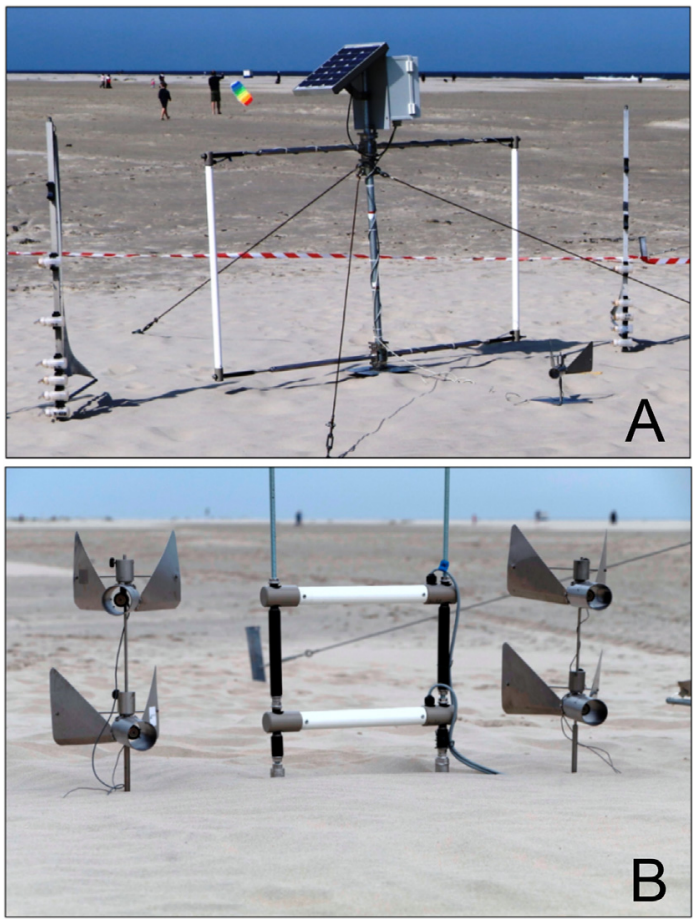

Fig. 3. Detail of the tested SandFlows. A: Long Sandflows 1 and 2; B: Short Sandflows 3 and 4.

approximately $1 \mathrm{~m}$ tall.

Two setups were constructed to test the SandFlow. In the first, Sandflow types SF4 and SF4-B (identified as SandFlow 1 and SandFlow 2 in this article) were installed vertically to a shared mast (Fig. 3A). On both sides of the SandFlow mast two MWAC masts with 7 sampling bottles each were erected. Vertical sand transport flux was measured with the MWACs during several wind erosion events. By integrating the sand transport flux over the same height interval as the operational section of the SandFlow, direct comparisons between the MWAC and the SandFlow can be made. We opted for the MWAC as the reference sampler because the efficiency of this sampler (measured against an isokinetic sampler) has been determined in previous studies, for different types of sand (Goossens et al., 2000).

In the second setup we compared the SandFlow with the Saltiphone. Two SF4-short sensors (identified as SandFlow 3 and SandFlow 4 in this article) were installed horizontally, the first at $35 \mathrm{~cm}$ and the second at $13 \mathrm{~cm}$ above the beach surface, in such a way that saltation could be adequately sampled. Adjacent and to each side of the SandFlows a Saltiphone was installed at the same height (Fig. 3B). Saltiphones 1 and 3 were installed at $13 \mathrm{~cm}$, and Saltiphones 2 and 4 at $35 \mathrm{~cm}$ above the beach surface. Particle transport was recorded by all instruments at 10second intervals. The output of the sensors was compared by relating the counts registered by the Saltiphones to the sand transport flux calculated by the SandFlows. All results were corrected for the measurement area of each instrument and for any changes in wind direction (also at 10-second intervals) that occurred during the experiment. Airborne sediment collected by the MWACs was analyzed for grain size distribution using a Malvern Mastersizer S laser particle size analyzer.

\subsection{Laboratory measurements}

Because the efficiency of most sensors used in particle transport depends on the size of the airborne particles, we tested the effect of sediment size on the efficiency of the SandFlow. Fig. 4 shows a scheme of the experimental set-up. The Sandflow sensor was placed horizontally above the ground, supported by two standards. A funnel was placed above the SandFlow to drop the sand on the instrument. The 


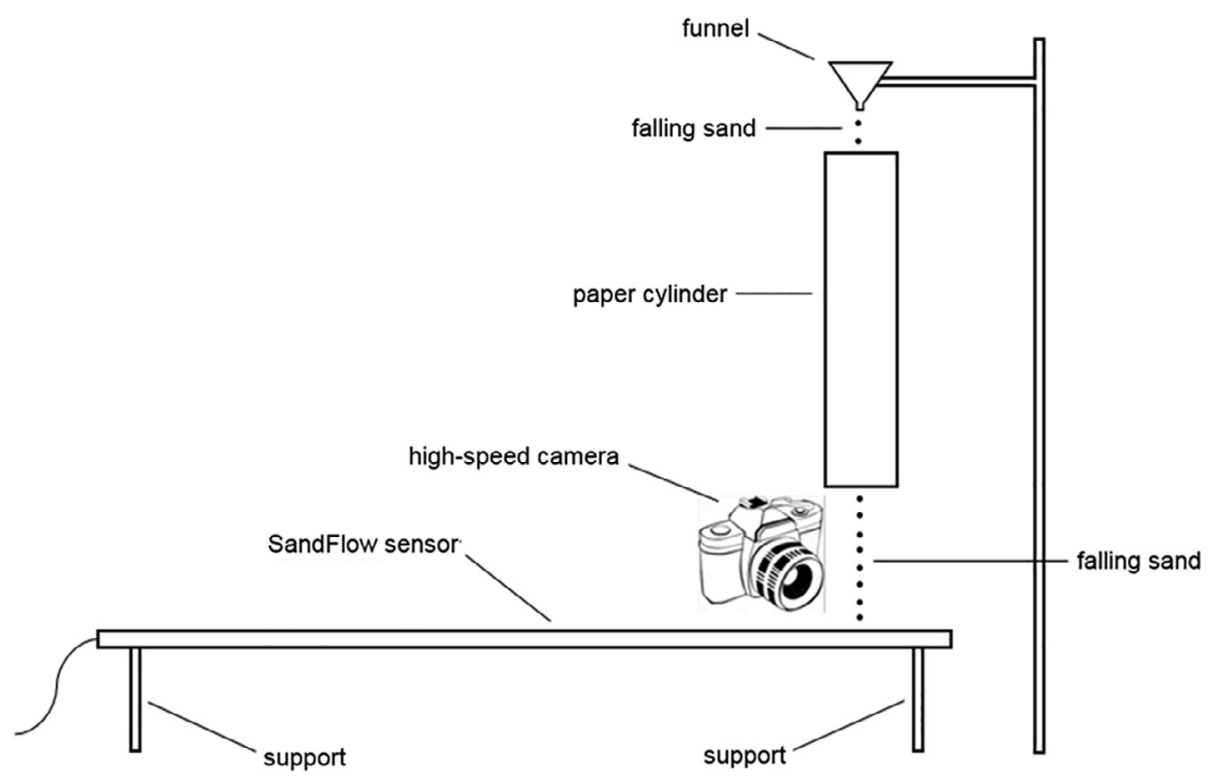

Fig. 4. Scheme of the experimental set-up for testing the effect of sediment size.

12 Aug 18:00 - 13 Aug 02:00
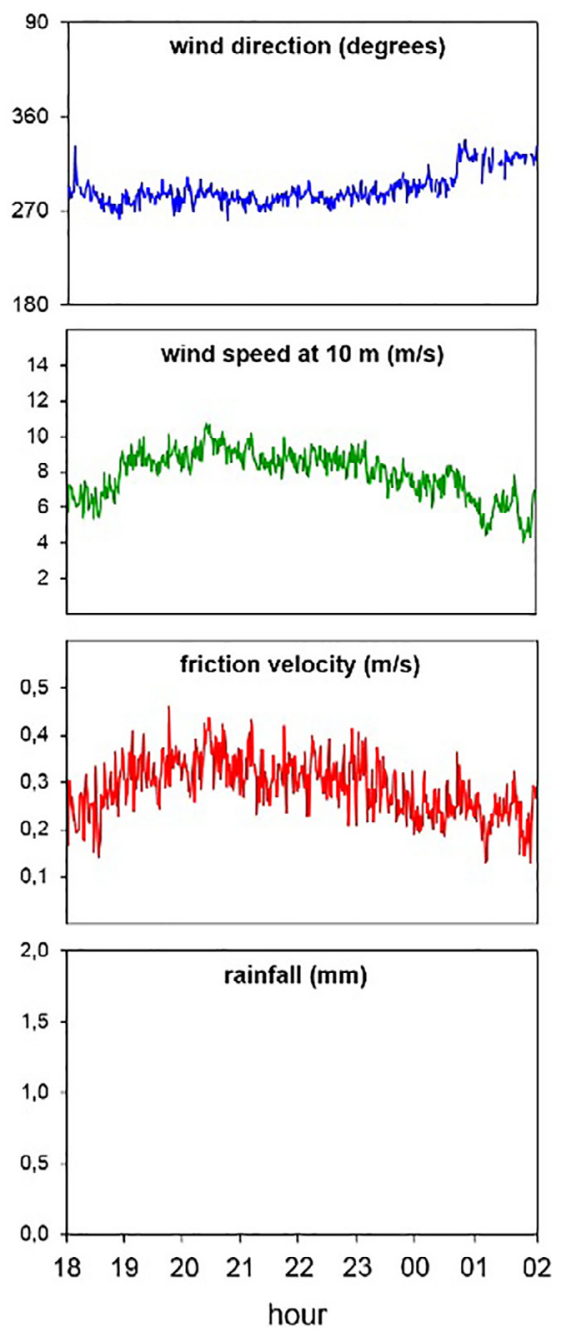

18 Aug 15:00 - 18 Aug 19:00
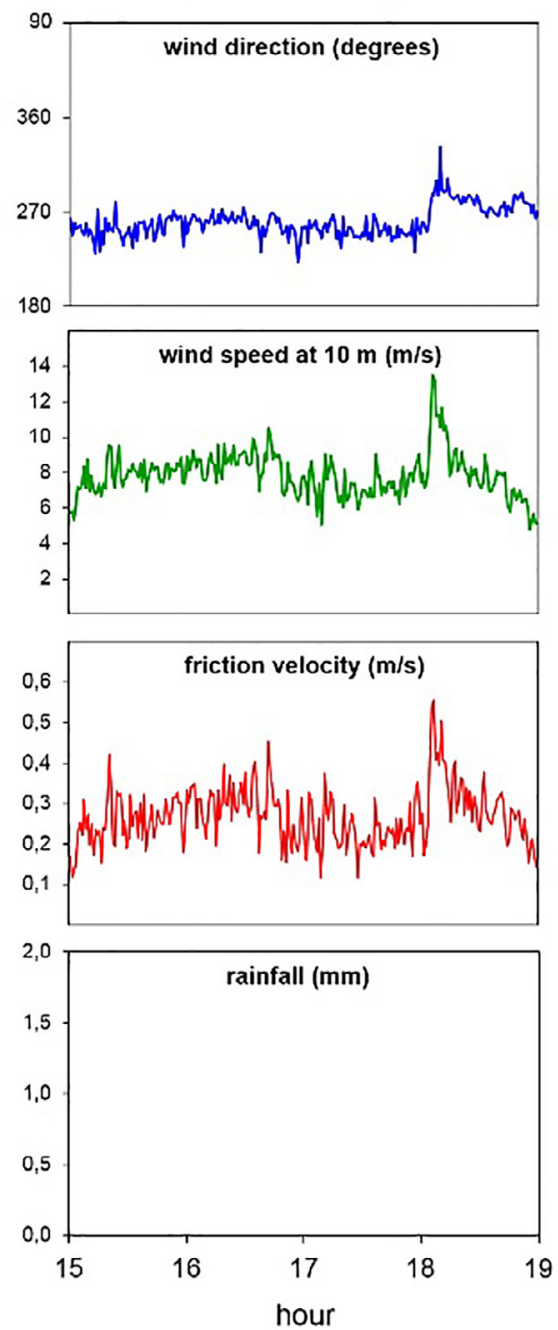

19 Aug 00:00 - 21 Aug 11:00
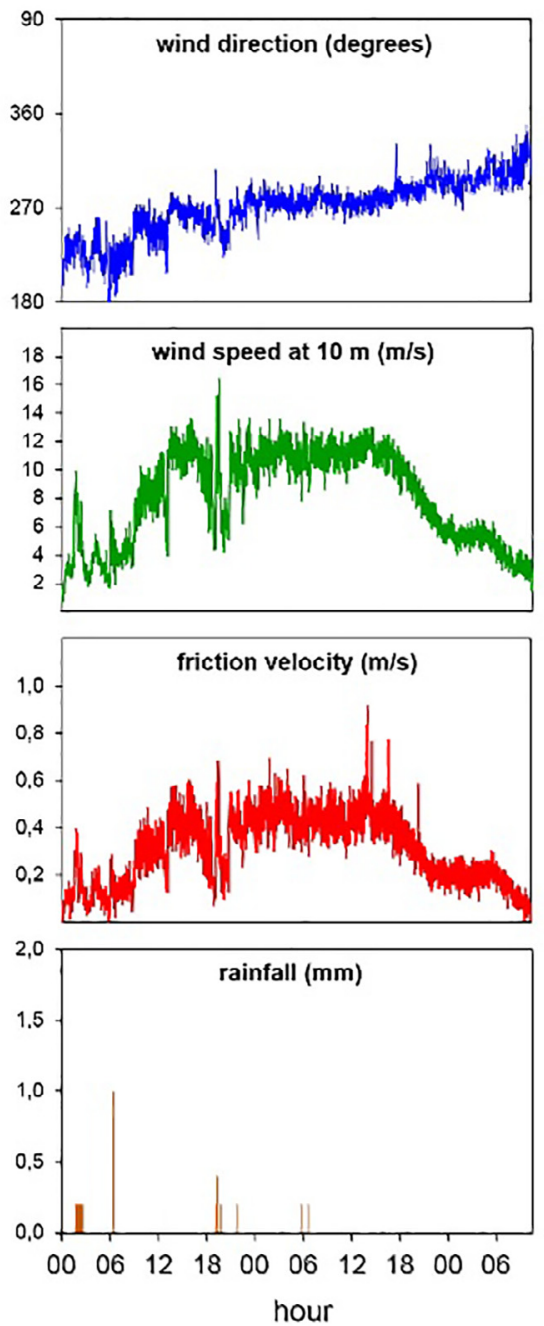

Fig. 5. Meteorology of the 3 wind erosion events that occurred during the experiment. 

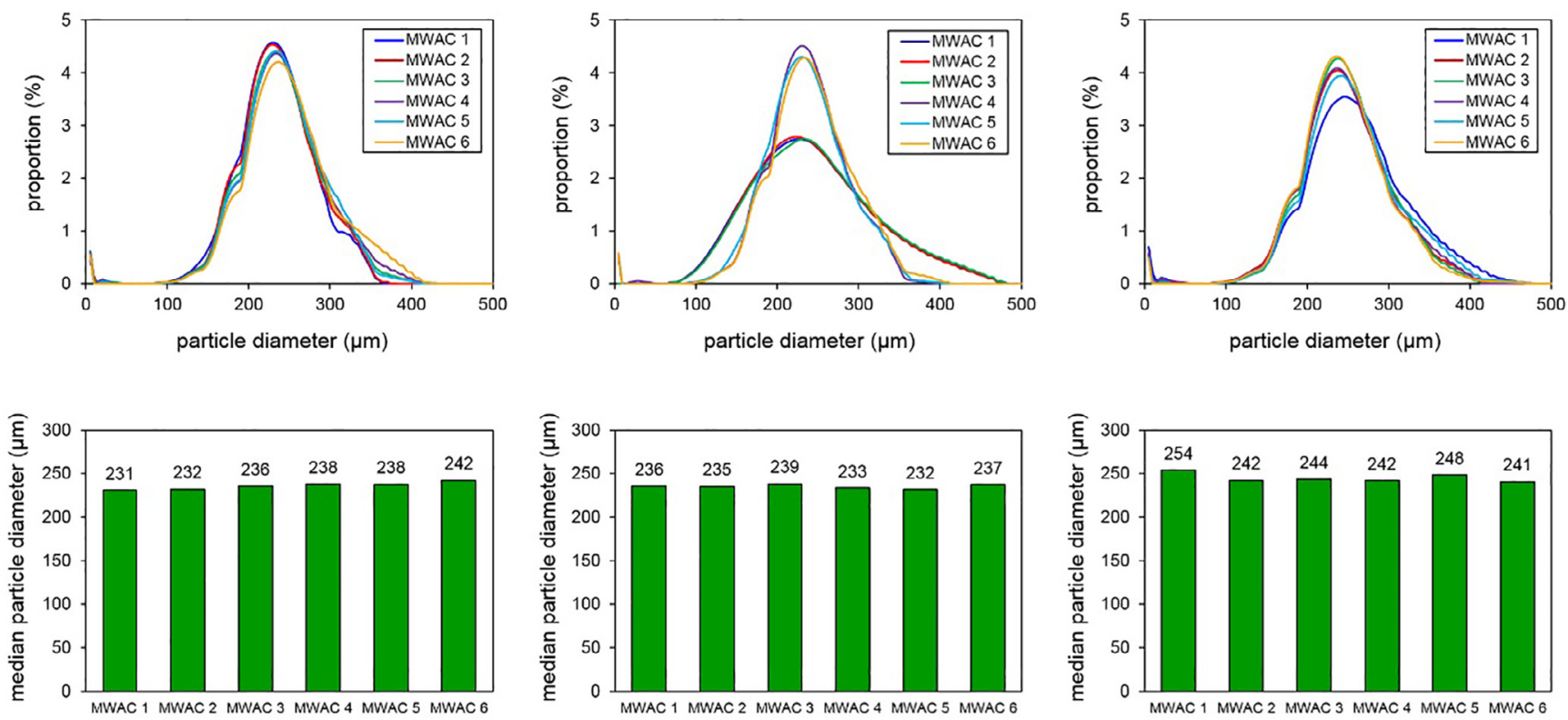

Fig. 6. Particle size distribution (upper graphs) and median particle diameter (lower graphs) of the airborne sediment.

12 Aug 18:00 - 13 Aug 02:00
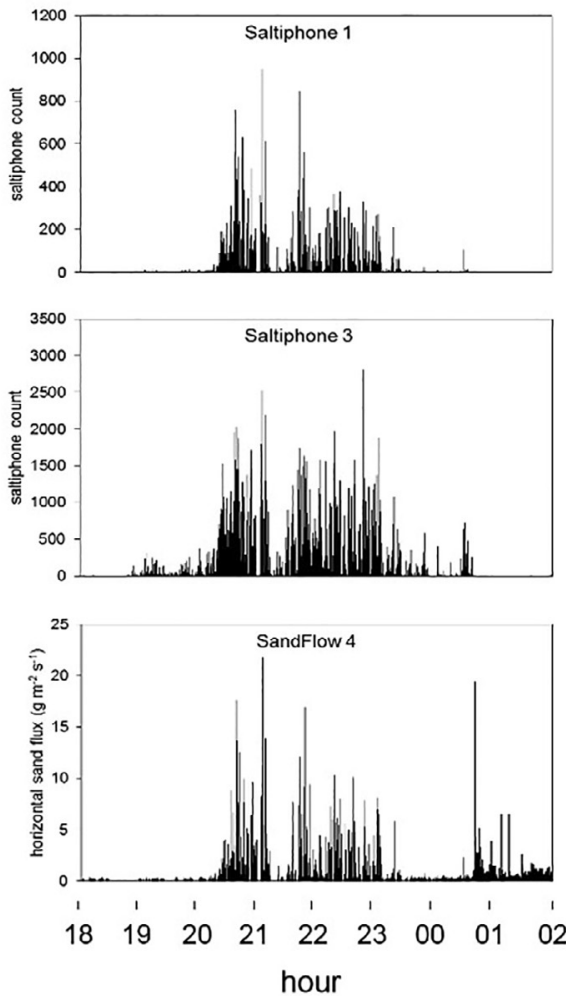

18 Aug 15:00 - 18 Aug 19:00
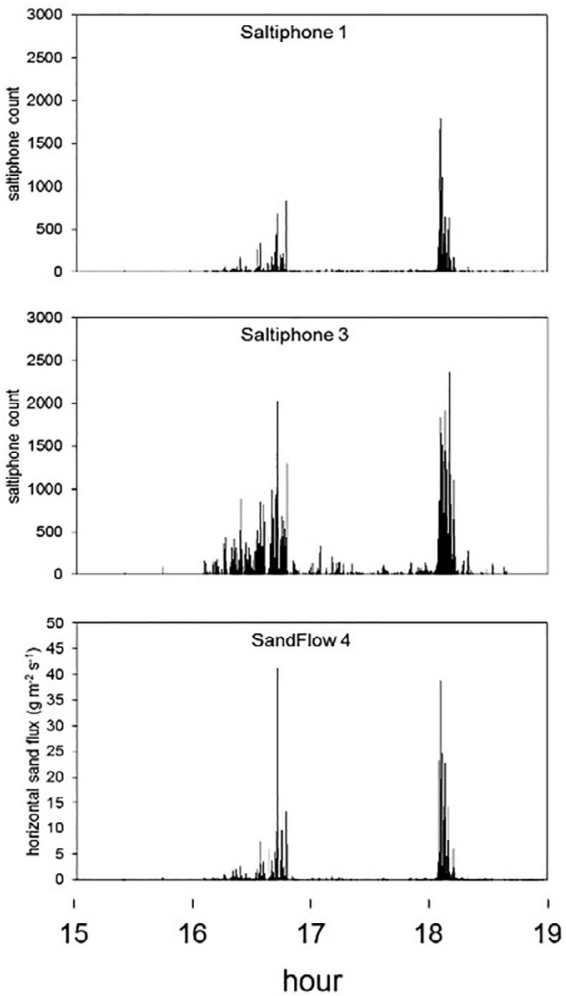

19 Aug 00:00 - 21 Aug 11:00
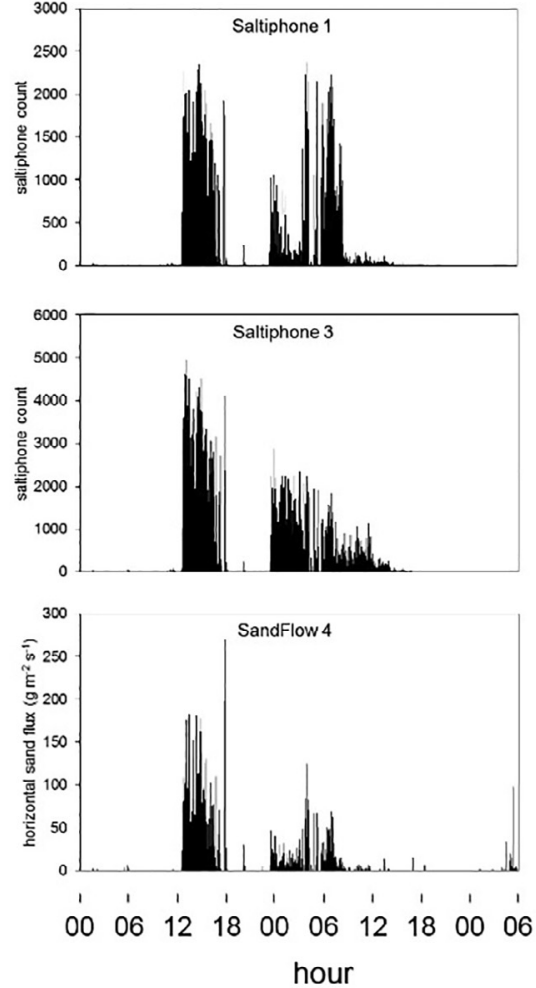

Fig. 7. Sand transport registration of the lower horizontal SandFlow (SandFlow 4) and the lower and adjacent Saltiphones 1 and 3.

path of the falling particles was surrounded by a paper cylinder to reduce any potential disturbances by accidental airflow from aside. The sand was dropped at the bottom of the sensor (the end where the transducer's unit has been attached) because during vertical installation of the sensor in the field, saltation took place in this zone.
For a field-representative calibration the kinetic energy of the falling sand should be similar to the kinetic energy during natural wind erosion. We used high-speed photography to measure the fall velocity of the particles and to determine the optimum fall height during the tests. The velocity of the falling sand was calculated from the change in 
12 Aug 18:00 - 13 Aug 02:00
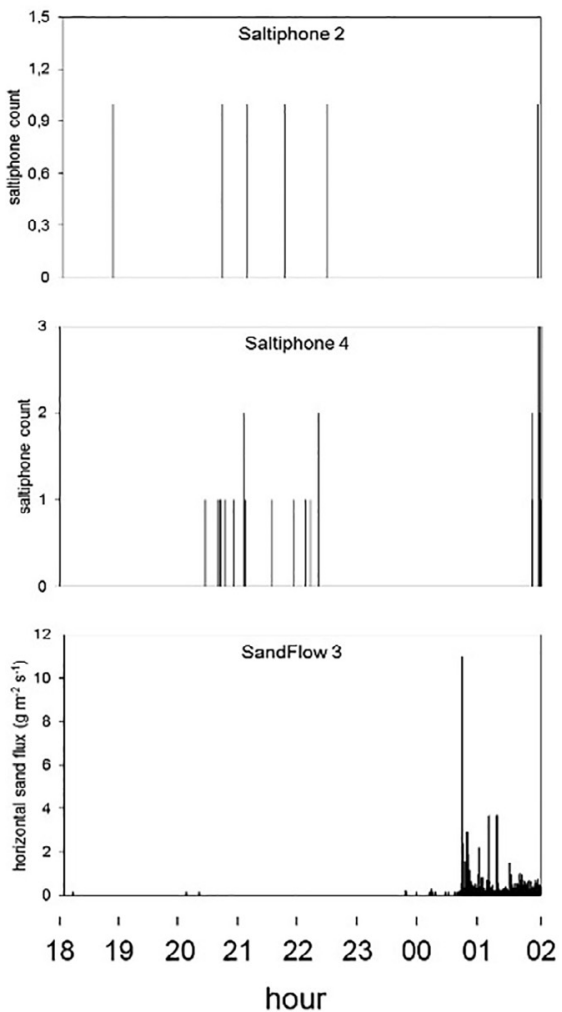

18 Aug 15:00 - 18 Aug 19:00
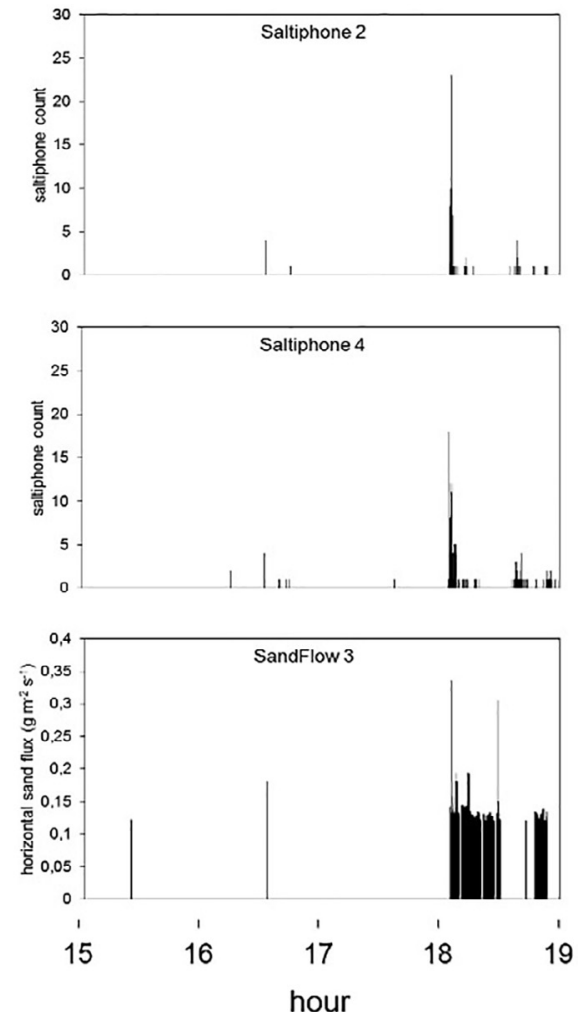

19 Aug 00:00 - 21 Aug 11:00
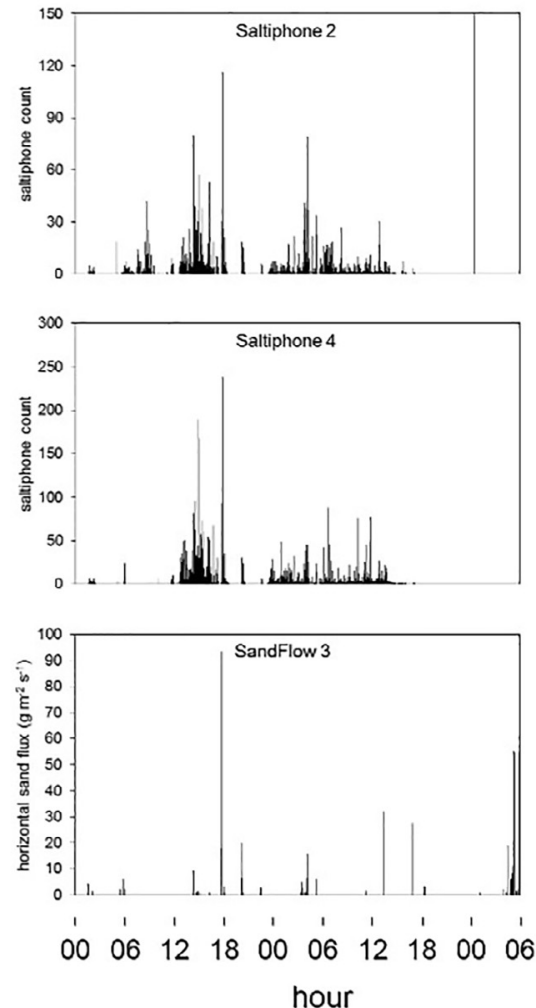

Fig. 8. Sand transport registration of the upper horizontal SandFlow (SandFlow 3) and the upper and adjacent Saltiphones 2 and 4.

position between two consecutive images taken within a known time interval. Based on the results, and taking into account the available height in the measurement room, a fall height of $100 \mathrm{~cm}$ above the SandFlow was selected. The fall velocities varied between $4.2 \mathrm{~m} \mathrm{~s}^{-1}$ (finest sand) and $5.5 \mathrm{~m} \mathrm{~s}^{-1}$ (coarsest sand) upon impact on the SandFlow, which is within the range of horizontal particle speed at wind erosion threshold conditions of common sandy surfaces (between 3 and $7 \mathrm{~m} \mathrm{~s}^{-1}$, see Baas \& van den Berg, 2018).

The following granulometrical fractions were tested: 0-106 $\mu \mathrm{m}$, 106-150 $\mu \mathrm{m}, \quad 150-250 \mu \mathrm{m}, \quad 250-300 \mu \mathrm{m}, \quad 300-450 \mu \mathrm{m}$, and $450-500 \mu \mathrm{m}$. The mass used for each fraction was selected based on the maximum flux that can be measured by the SandFlow $\left(250 \mathrm{~g} \mathrm{~m}^{-2} \mathrm{~s}^{-1}\right)$.

Efficiency $(E)$ of the SandFlow was calculated using the following equation:

$E=\frac{Q}{q}$

where $Q$ is the sediment flux measured by the SandFlow and $q$ the real flux as determined during the experiment. The real flux was calculated by dividing the weight of the fallen sand by the time it took for the sand to fall and the area on the SandFlow the sand fell on. The weight of the fallen sand was corrected for any sand that was left behind in the funnel and for any sand that did not hit the SandFlow. Time was measured with a stopwatch. To measure the amount of sand that did not hit the SandFlow but fell aside of it we repeated the experiment (in triplicate), where the SandFlow was replaced with a tray with the same width and length.

\section{Results}

\subsection{Field results}

\subsubsection{Meteorology}

A total of 3 wind erosion events occurred during the field experiment. Event 1 (12 August 2017 18:00 to 13 August 2017 02:00) took 8 h, event 2 (18 August 2017 15:00 to 18 August 2017 19:00) took 4 h, and event 3 (19 August 2017 00:00 to 21 August 2017 11:00) took $59 \mathrm{~h}$. During event 3 two erosive periods occurred, separated by a calmer period where almost no wind erosion was recorded. Fig. 5 shows the wind direction, wind speed (at standard height of $10 \mathrm{~m}$ ), friction velocity, and rainfall during the 3 events.

\subsubsection{Grain size distribution of the airborne sediment}

Airborne sand was collected with the MWACs at heights of 6, 13, 20, 27, 45 and $70 \mathrm{~cm}$ above the beach surface (events 1 and 2) and 16, 23, 30,3755 and $80 \mathrm{~cm}$ (event 3 , which was very erosive). The 7th collection bottle, installed at a height of $100 \mathrm{~cm}$ (events 1 and 2) or $110 \mathrm{~cm}$ (event 3), was above the sand transport layer and did not collect any sand. A laser particle size analyzer was used to determine a detailed grain size distribution of the collected samples. Fig. 6 shows the grain size curves (upper graphs) and the median diameters (lower graphs). Grain size was fairly constant during the experiment and did not vary with the height. The average median diameter was $239 \mu \mathrm{m}$.

\subsubsection{Registration of sand transport}

To test the ability of the SandFlow to register the episodes of aeolian sand transport we compared the instrument to the Saltiphone. The Saltiphone has been shown to accurately record the occurrence of sand transport (Poortinga et al., 2013; Goossens et al., 2018) and is thus a good reference sampler.

The registrations of sand transport during each wind erosion event 
12 Aug 18:00 - 13 Aug 02:00
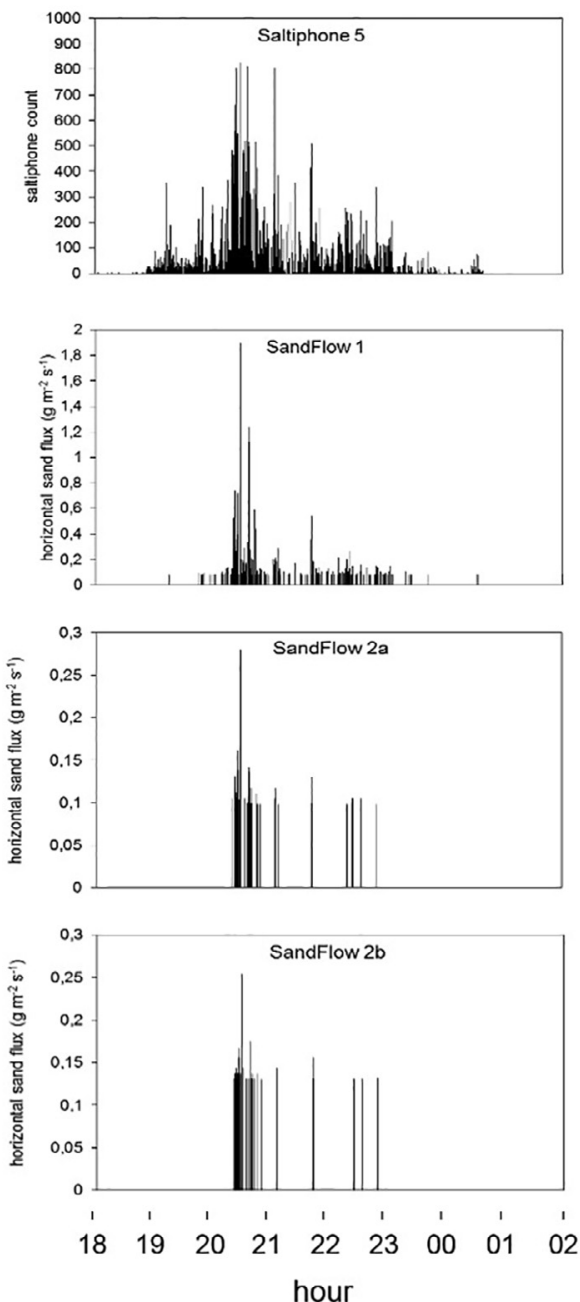

18 Aug 15:00 - 18 Aug 19:00
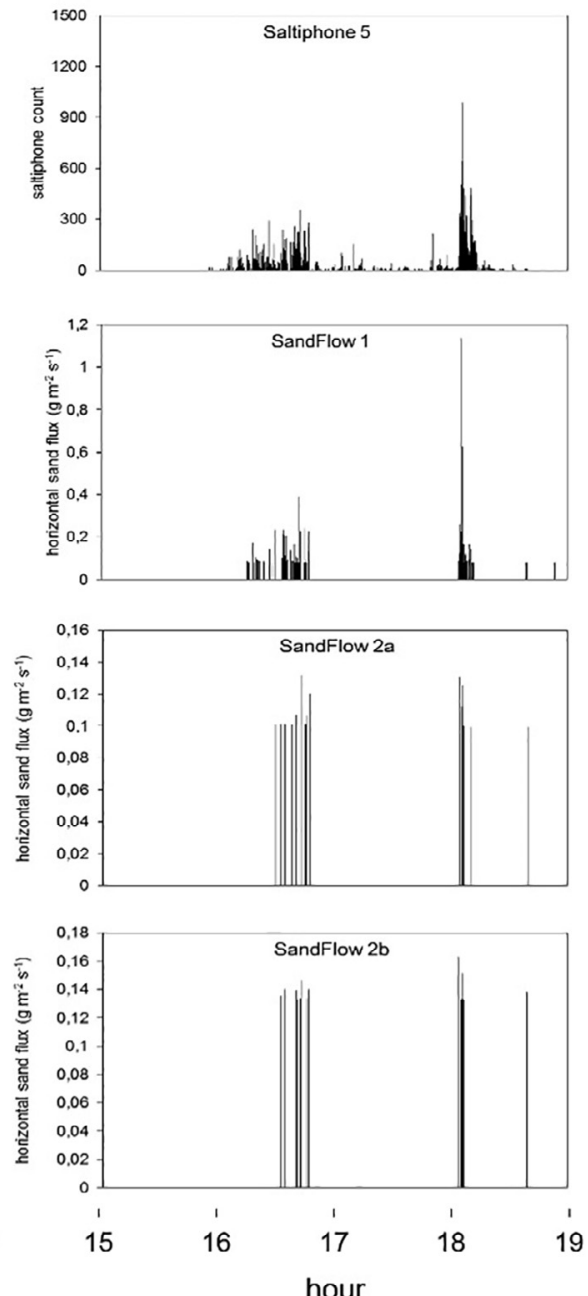

19 Aug 00:00 - 21 Aug 11:00
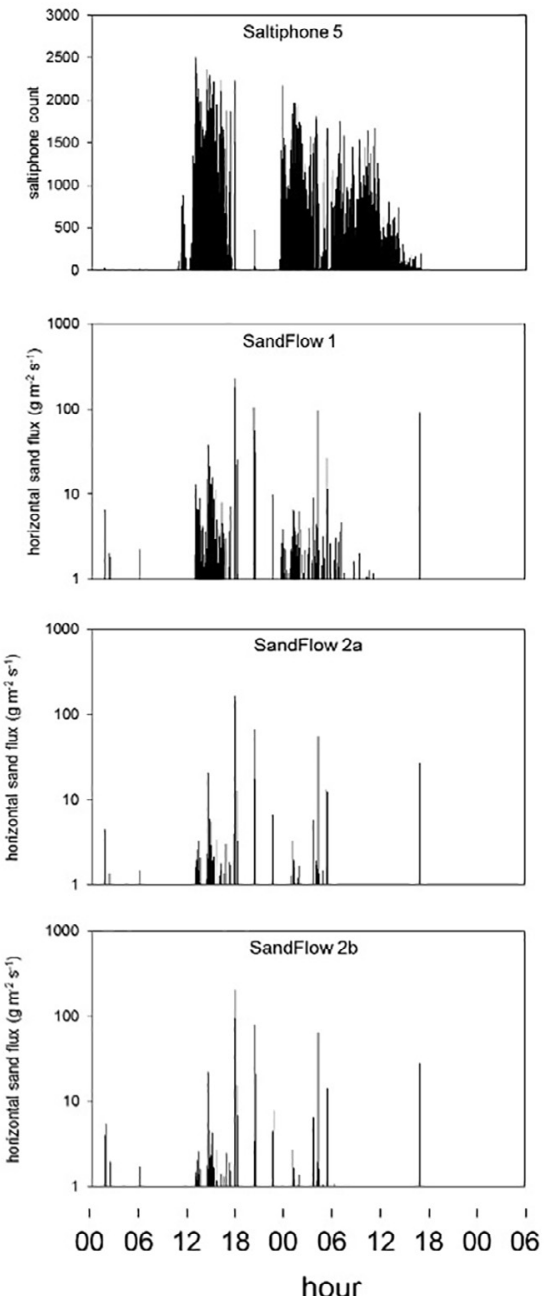

Fig. 9. Sand transport registration of the vertical SandFlows 1 and 2 and Saltiphone 5. Separate information is shown for SandFlows 2a and 2b.

Table 2

Vertically integrated sand flux measured by vertical SandFlows 1 and 2 (average of $2 \mathrm{a}$ and $2 \mathrm{~b}$ ) compared to the vertically integrated sand flux measured by MWAC masts 2 and 3 .

\begin{tabular}{clll}
\hline Wind erosion event & $\begin{array}{l}\text { Vertically integrated sand flux } \\
\left(\mathrm{g} \mathrm{m}^{-2} \mathrm{~s}^{-1}\right)\end{array}$ & $\begin{array}{l}\text { Ratio flux SF/ } \\
\text { MWAC }\end{array}$ \\
\hline 12 Aug 18:00 - 13 Aug & SF 1 & MWAC 2 & SF 1/MWAC 2 \\
$02: 00$ & 0.0153 & 0.0115 & 1.3307 \\
& SF 2 & MWAC 3 & SF 2/MWAC 3 \\
& 0.0020 & 0.0145 & 0.1361 \\
18 Aug 15:00 - 18 Aug & SF 1 & MWAC 2 & SF 1/MWAC 2 \\
$19: 00$ & 0.0090 & 0.0131 & 0.6842 \\
& SF 2 & MWAC 3 & SF 2/MWAC 3 \\
19 Aug 00:00 - 21 Aug & 0.0015 & 0.0157 & 0.0946 \\
$11: 00$ & SF 1 & MWAC 2 & SF 1/MWAC 2 \\
& 0.3562 & 2.2003 & 0.1619 \\
& SF 2 & MWAC 3 & SF 2/MWAC 3 \\
& 0.1840 & 2.5513 & 0.0721
\end{tabular}

are shown in Figs. 7-9. Fig. 7 shows the data for the lower horizontal SandFlow 4 and the lower and adjacent Saltiphones 1 and 3; Fig. 8 the data for the upper horizontal SandFlow 3 and the upper and adjacent Saltiphones 2 and 4; and Fig. 9 the data for the long vertical SandFlows 1 and 2 and Saltiphone 5. Separate information is provided in Fig. 9 for SandFlow 2a and SandFlow 2b. The figures indicate that the registrations were comparable between the instruments, particularly when intense sand transport occurred. When sand transport was less intense, the agreement between the instruments was lower although in many cases the periods of sand transport were still detected. For the entire experiment the agreement in detecting sand transport (yes/no) between the instruments was as follows: Saltiphone 1 and SandFlow 4: 94\%; Saltiphone 3 and SandFlow 4: 92\%; Saltiphone 5 and SandFlow 1: 90\%; Saltiphone 5 and SandFlow 2a: 89\%, and Saltiphone 5 and SandFlow 2b: $89 \%$. These numbers refer to the 10 -second measurement time intervals applied in the test. From these data we conclude that the SandFlow instrument detects episodes of aeolian sand transport.

\subsubsection{Quantification of sand transport}

Contrary to the Saltiphone, whose efficiency to measure the intensity of sand transport varies with the particle size of the sediment and the wind speed, the efficiency of the MWAC is fairly constant for sand-sized particles. To test the ability of the SandFlow to accurately quantify aeolian sand transport we therefore compared the sand transport flux measured by the SandFlow to the sand transport flux measured by the MWAC.

Table 2 compares the vertically integrated sand flux that was measured by the vertical SandFlows 1 and 2 (average of SandFlows 2a and $2 \mathrm{~b}$ ) to the vertically integrated sand flux that was measured by the MWAC masts 2 and 3 that were installed adjacent to respectively SandFlow 1 and SandFlow 2. For the MWAC an efficiency of $120 \%$ was 

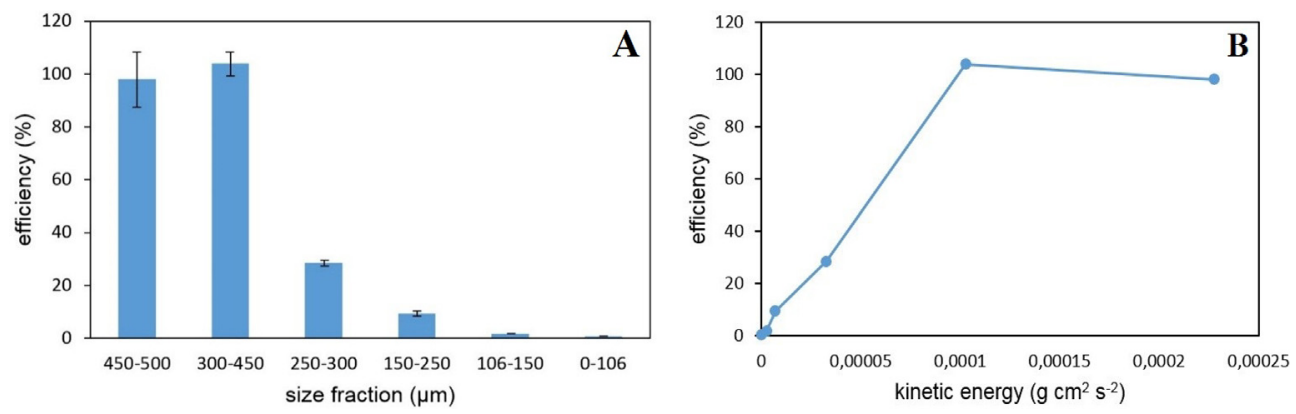

Fig. 10. Efficiency of the SandFlow A: for different particle size fractions; B: as a function of kinetic energy. Error bars represent the standard deviation.

assumed, as shown by the study by Goossens et al. (2000). In general, the fluxes measured by the SandFlow are lower than those measured by the MWAC (Table 2), on the order of 10 times lower, except for SF1 during events 1 and 2 where higher efficiencies were measured. One should realize that during aeolian sand transport particle movement usually occurs in streamers, which creates some variation in the spatial distribution of the transport flux. Identical transport fluxes are therefore not to be expected, but the measured fluxes can be expected to be within the same order of magnitude and this was the case for all three wind erosion events on Terschelling.

\subsection{Laboratory results: Effect of sediment size}

Fig. 10 shows the efficiency of the SandFlow for different particle size fractions and as a function of kinetic energy as measured during the laboratory tests. The data represent the average of three replicate experiments. Variation between the experiments was always small, as indicated by the vertical error bars. Results show that particle size does have an effect on the efficiency of the SandFlow. The coarser the sediment, the higher the efficiency of the instrument becomes. A minimum kinetic energy of $0.0001 \mathrm{~g} \mathrm{~cm}^{2} \mathrm{~s}^{-2}$ is needed to get an efficiency of $100 \%$. The minimum wind speeds necessary for the SandFlow to attain an efficiency of $100 \%$ were $3.7,5.3,8.4,16.4$, and $26.3 \mathrm{~m} \mathrm{~s}^{-1}$ for the fractions 450-500, 300-450, 250-300, 150-200, 106-150, and $0-106 \mu \mathrm{m}$, respectively. Efficiency is excellent (98\% and 104\%) for the coarsest particle fractions (450-500 $\mu \mathrm{m}$ and $300-450 \mu \mathrm{m}$, respectively) but decreases rapidly when particles become finer. For the fraction $250-300 \mu \mathrm{m}$ measured efficiency had decreased to $28 \%$, and for the fraction $150-250 \mu \mathrm{m}$, to $9 \%$. For the finest particles efficiency of the SandFlow was very low, less than $2 \%$.

\section{Evaluation and conclusions}

The field experiments on Terschelling show that the SandFlow adequately registers the periods of aeolian sand transport provided sand transport is sufficiently intense (Figs. 7-9). For low sand transport the SandFlow is less accurate although the periods with sand transport may still be detected. Further research is needed to assess the threshold value of the transport rate above which transport is still registered by the SandFlow.

The field results also show that, in general, the sand transport fluxes measured by the SandFlow were lower than those measured by the MWAC although they remained within the same order of magnitude (Table 2). This is almost certainly explained by the rather low efficiency of the SandFlow for Terschelling sand, as shown by the laboratory fall tests. The median diameter of the Terschelling sand was $239 \mu \mathrm{m}$ (Fig. 6). Interpolating the data in Fig. 10, for sand of this size an efficiency of approximately $17 \%$ can be expected for the SandFlow. Apart from SF1 during erosion event 1 this corresponds reasonably well with the average efficiency measured during the field experiments (23\%) although the differences between the experiments are sometimes large (Table 2). Note that for SF1 during erosion event 1 the data are different in that the SandFlow measured a higher flux than the MWAC. The reason for this discrepancy remains unclear.

We conclude that the underestimation of the fluxes by the SandFlow compared to the MWAC (Table 2) is most likely explained by the rather low efficiency of the SandFlow for Terschelling sediment. For coarser sand the agreement between the SandFlow fluxes and the MWAC fluxes will probably become better, as suggested by the higher efficiencies for such sand in Fig. 10.

A limitation of the SandFlow is that the maximum flux it can read is restricted to $250 \mathrm{~g} \mathrm{~m}^{-2} \mathrm{~s}^{-1}$. During periods of heavy wind erosion the sand transport flux can reach values well beyond this limit. Such intense erosion events will thus be underestimated by the SandFlow, although the temporal occurrence of sand transport will still be registered correctly.

Despite the limitations in registration and efficiency (for particles finer than $300 \mu \mathrm{m}$ in diameter) the SandFlow also has several advantages compared to other sand transport measuring devices. It is a robust sampler that measures omnidirectional, so that no wind-rotating accessories are necessary. In addition, the instrument can work with any desired length of tube provided sufficient space is available to house the internal electronics. The instrument also suits well for long measuring periods. Very interesting is that simultaneously with the transport flux measurements, the instrument also measures the wind speed, at the same time resolution of the flux measurements. Experiments with the wind speed option activated (not reported here) showed that variations in wind speed were correctly registered, although more factory calibration (currently ongoing) was needed to replicate the values that were registered by the classic wind anemometers. A last advantage of the instrument is that it can directly measure the vertically integrated sand flux over the entire length of the measuring tube. Other sand transport devices perform point (or almost point) measurements so that the vertically integrated flux should be derived from curve fitting, or they measure over only short vertical distances. The standard length of the SandFlow is $100 \mathrm{~cm}$, well enough to capture all airborne sand during normal wind erosion events.

Although originally developed to measure snow transport, this study shows that the SandFlow can also be used for registering aeolian sand transport events provided transport is strong enough. In its current state of development, to obtain reliable quantitative flux data particles should preferably be coarser than $300 \mu \mathrm{m}$. Further technical improvements are necessary to lower this limit.

\section{CRediT authorship contribution statement}

Mahrooz Rezaei: Data curation, Formal analysis, Investigation, Methodology, Software, Validation, Writing - original draft, Writing review \& editing. Dirk Goossens: Conceptualization, Formal analysis, Funding acquisition, Investigation, Supervision, Validation, Writing original draft, Writing - review \& editing. Michel J.P.M. Riksen: Conceptualization, Data curation, Funding acquisition, Methodology, Supervision, Validation, Writing - review \& editing. 


\section{Acknowledgements}

IAV Technologies prepared the different configurations of the SandFlow sensors and provided funding for the field experiments. Apart from this technical support, no conflict of interest exists between the authors and IAV Technologies regarding relationships, results, interpretations, and/or conclusions obtained or made during this study and the preparation of the manuscript.

\section{References}

Baas, A.C., 2004. Evaluation of saltation flux impact responders (safires) for measuring instantaneous Aeolian sand transport intensity. Geomorphology 59, 99-118.

Baas, A.C.W., van den Berg, F., 2018. Large-scale particle image velocimetry (LSPIV) of aeolian sand transport patterns. Aeolian Res. 34, 1-17.

Barchyn, T.E., Hugenholtz, C.H., Li, B., McKenna Neuman, C., Steven Sanderson, R., 2014. From particle counts to flux: wind tunnel testing and calibration of the 'Wenglor' aeolian sediment transport sensor. Aeolian Res. 15, 211-318.

Bauer, B.O., Davidson-Arnott, R.G.D., Hilton, M.J., Fraser, D., 2018. On the frequency response of a Wenglor particle-counting system for aeolian transport measurement. Aeolian Res. 32, 133-140.

Bauer, B.o., Namikas, S.L., 1998. Design and field test of a continuously weighting tipping-bucket assembly for Aeolian sand traps. Earth Surf. Proc. Land. 23, 1171-1183.

Chritin, V., 1998. Flowcapt: un capteur dans le vent. Neige et Avalanches 81, 13-15.

Chritin, V., Bolognesi, R., Gubler, H., 1999. FlowCapt: a new acoustic sensor to measure snowdrift and wind velocity for avalanche forecasting. Cold Reg. Sci. Technol. 30, 125-133.

Cierco, F.X., Naaim-Bouvet, F., Bellot, H., 2007. Acoustic sensors for snowdrift measurements: how should they be used for research purposes? Cold Reg. Sci. Technol. 49, 74-87.

Duarto-Campos, L., Wijnberg, K.M., Oyarte-Galvez, L., Hulscher, S.J.M.H., 2017. Laser particle counter validation for Aeolian sand transport measurements using a highspeed camera. Aeolian Res. 25, 37-44.

Ellis, J.T., Morrison, R.F., Priest, B.H., 2009. Detecting impacts of sand grains with a microphone system in field conditions. Geomorphology 105, 87-94.

Etyemezian, V.R., Nikolich, G., Nickling, W.G., King, J., Gillies, J.a., 2017. Analysis of an optical gate device for measuring Aeolian sand movement. Aeolian Res. 24, 65-79. Gillette, D., Stockton, P., 1989. The effect of nonerodible particles on wind erosion of erodible surfaces. J. Geophys. Res. - Atmosp. 94, 12885-12893.

Gillies, J.A., Nickling, W.G., King, J., 2006. Aeolian sediment transport through large patches of roughness in the atmospheric interial sublayer. J. Geophys. Res. - Earth Surf. 111, F02006.

Goossens, D., Nolet, C., Etyemezian, V., Duarte-Campos, L., Bakker, G., Riksen, M., 2018. Field testing, comparison, and discussion of five aeolian sand transport measuring devices operating on different measuring principles. Aeolian Res. 32, 1-13.

Goossens, D., Offer, Z.Y., London, G., 2000. Wind tunnel and field calibration of five aeolian sand traps. Geomorphology 35, 233-252.

Hugenholtz, C.H., Barchyn, T.E., 2011. Laboratory and field performance of a laser particle counter for measuring Aeolian sand transport. J. Geophys. Res.: Earth Surf. 116, F01010.

Jackson, D.W.T., 1996. A new, instantaneous Aeolian sand trap design for field use. Sedimentology 43, 791-796.

Janssen, W., Tetzlaff, G., 1991. Entwicklung und Eichung einer registrierenden Suspensionsfalle. Z. Kulturtech. Landesentwickl. 32, 167-180.

Lancaster, N., Nickling, W.G., Gillies, J.A., 2010. Sand transport by wind on complex surfaces: field studies in the McMurdo Dry Valleys, Antarctica. J. Geophys. Res. Earth Surf. 115, F03027.

Lee, J.A., 1987. A field experiment on the role of small scale wind gustiness in Aeolian sand transport. Earth Surf. Proc. Land. 12 (3), 331-335.

Mikami, M., Yamada, Y., Ishizuka, M., Ishimaru, T., Gao, W., Zeng, F., 2005. Measurement of saltation process over gobi and sand dunes in the Taklimakan desert, China, with newly developed sand particle counter. J. Geophys. Res. 110, D18s02.

Poortinga, A., van Minnen, J., Keijsers, J., Riksen, M., Goossens, D., Seeger, M., 2013. Measuring fast-temporal sediment fluxes with an analogue acoustic sensor: a wind tunnel study. PLoS One 8, e74007. https://doi.org/10.1371/journal.pone.0074007.

Schmutz, P., Briggs, T., Tereszkiewicz, P., 2019. The utility of an omni-directional photoelectronic sensor device to measure meso-scale variability in Aeolian sediment transport activity. Aeolian Res. 36, 61-67.

Spaan, W., Van den Abeele, G., 1991. Wind borne particle measurements with acoustic sensors. Soil Technol, 4, 51-63.

Sterk, G., Raats, P.A.C., 1996. Comparison of models describing the vertical distribution of wind-eroded sediment. Soil Sci. Soc. Am. J. 60, 1914-1919.

Stockton, P., Gillette, D.A., 1990. Field measurements of the sheltering effect of vegetation on erodible land surfaces. Lan Degrad. Rehabil. 2, 77-85. 